\title{
Harnessing the Potential of Adenovirus Vectored Vaccines
}

\author{
Peter Johannes Holst, \\ Jan Pravsgaard Christensen and Allan Randrup Thomsen \\ Department of International Health, Immunology and Microbiology, \\ University of Copenhagen, Copenhagen, \\ Denmark
}

\section{Introduction}

A range of infectious diseases and cancers are in theory preventable or treatable by vaccination, but have remained outside the reach of traditional vaccination. This may be because of special problems regarding the selection of appropriate target antigens or certain requirements regarding the quality of the vaccine induced response. In this context, the use of recombinant virus vectored vaccines may be a promising future concept that combines important features of live attenuated vaccines with greater safety and the ability to target any imaginable antigen. Among the virus vectors investigated for vaccine purposes, adenovirus vectors have received considerable attention and today stand among the most potent tools available for induction of antibody and CD8+ T cell responses in mice, primates and humans (Barefoot et al., 2008; Bett et al., 2010; Shiver et al., 2002). Adenovirus vectored vaccines has, however, also been implicated in one of the most spectacular HIV vaccine failures (Buchbinder et al., 2008), and some papers describe either undesirable attributes of the adenovirus induced $\mathrm{T}$ cell response or properties of vector specific responses, which may increase mucosal HIV transmission (Benlahrech et al., 2009; Perreau et al., 2008). The current review will attempt to describe the key features of adenovirus vectored vaccine induced immune responses, the mechanisms underlying induction of different response qualities, how the adenovirus vectors compare with other vaccination tools in the immunological arsenal, and how adenovirus vectors can be combined in heterologous vaccination regimens. A final section will be dedicated to potential future clinical application of adenovirus vectored vaccines.

\section{Immune responses against adenovirus vectored vaccines - the issue of magnitude and functionality}

Although scientific progress had been made using replication incompetent adenovirus vectors for vaccination since the late 1980's (Alkhatib \& Briedis, 1988) (see figure 1 for a description of the principal immunological differences between replication competent and replication incompetent adenovirus vectors), the interest in this vector system exploded with the demonstration of antiviral efficacy against simian human immunodeficiency virus (SHIV) of a vaccine encoding SIV gag delivered by a human serotype 5 adenovirus vector in non-human 
primates (NHPs)(Shiver et al., 2002). The failure of modified vaccinia Ankara (MVA) or DNA vectors to achieve similar results only served to underscore the potency of the adenoviral vector system. However, several reports both preceding and in particularly following the spectacular failure of the MERCK STEP trial have highlighted that adenoviral vectored vaccines may induces a substantial, yet functionally impaired T cell response (Tatsis et al., 2007a), that in many cases nevertheless provide highly significant protection (Yang et al., 2006). In that context it is pertinent to note, that adenoviral vaccination seems to induce $T$ cells with a phenotype more resembling that associated with a chronic infection than with a resolved acute and selflimiting infection. Importantly, although the kinetics and magnitude of the reported adenovirus induced CD8+ T cell responses vary considerably depending on the encoded antigen as well as the route and dose of immunization, the responses are unusually stable over time. Thus, memory $\mathrm{T}$ cell frequencies frequently stabilizes above $30 \%$ of the peak response, which contrast with the 5-10\% usually found to be associated with acutely resolved infections (Abbink et al., 2007; Holst et al., 2007; Holst et al., 2010b; Tatsis et al., 2007a) (See figure 2 for a cartoon of the different immune response patterns and their associated phenotypic properties).
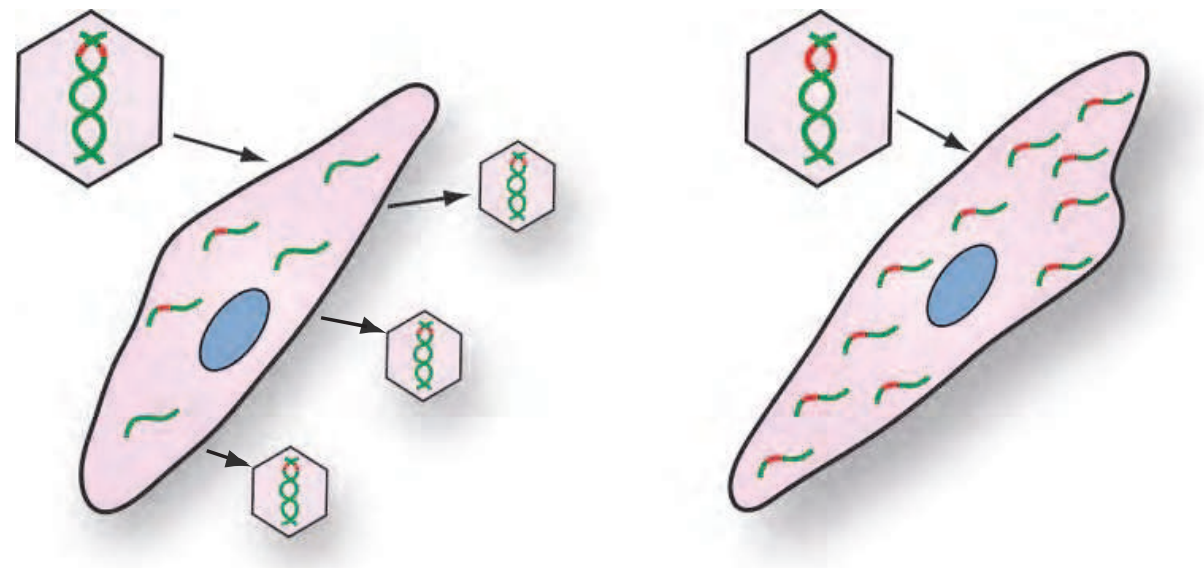

Fig. 1. The principal differences between replication competent and replication incompetent viral vectors with regard to source of antigens. Infection with a live replication competent vaccine vector (left side) or a replication incompetent vector (right side) differ markedly in the ability to present recombinant vaccine antigen. The replication competent vector has less cloning capacity (hence the small red fragment symbolizing recombinant antigen) and infection of a host cell results in many viral transcripts being produced, including those not containing the recombinant insert. On the positive side, the inoculum will be amplified (symbolized by the appearance of virus progeny), and present an ongoing infectious signature to the innate immune system. Replication incompetent vectors do not become amplified, but transcripts containing the recombinant insert dominate the transcription profile of the transduced cell. Other popular virus vectors such as vaccinia virus resemble replication competent adenovirus in the way in which they present antigen, whereas replication deficient variants, such as modified vaccinia Ankara (MVA), more resemble replication incompetent vectors (although with more non-recombinant gene expression) 


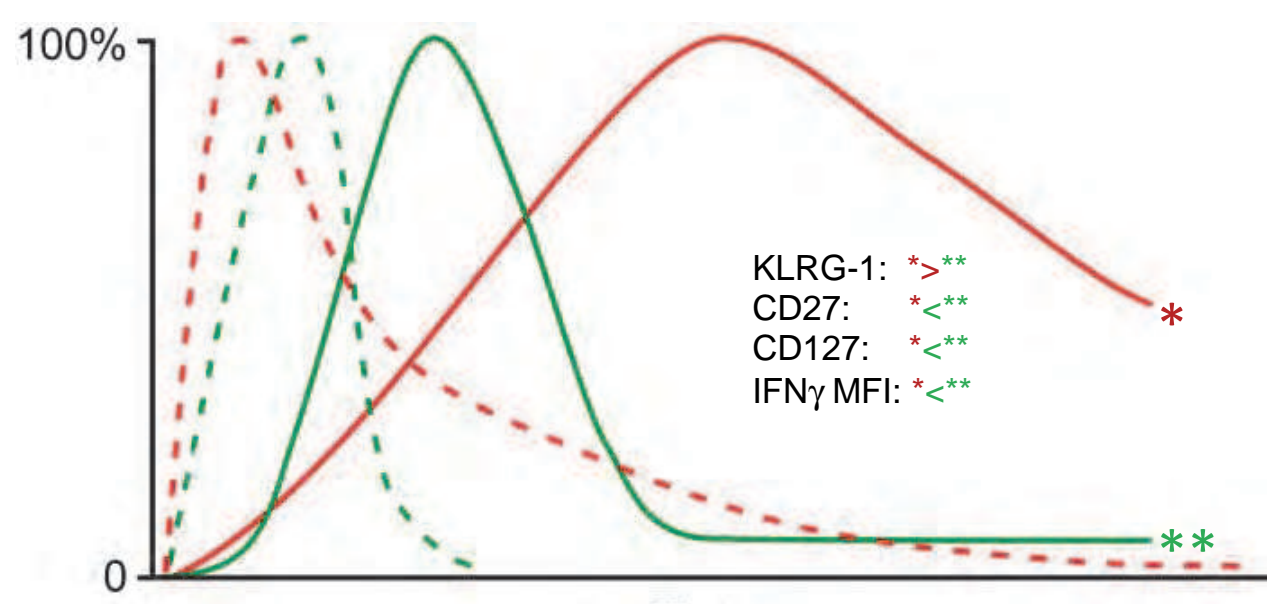

Time

Fig. 2. The principal time-course of antigen elimination and CD8+ $\mathrm{T}$ cell response after a self-limiting acute infection and an adenoviral vaccination. Infection with an acute viral infection (green lines)) takes days to reach maximal antigen presentation (dashed green line) as viral replication is needed to amplify the inoculum. There is rapid and nearly complete elimination of the virus after the peak by the induced CD8+ T cell response (full green line) the time-course of which mimics the antigen curve with a few days delay. Vaccination with a replication incompetent adenoviral vector (red lines) is representing a bolus injection and the peak of antigen expression (dashed red line) is reached shortly after virus inoculation. Subsequently antigen presentation gradually declines over a protracted time-period. T cell expansion is delayed (full red line) and slowly reaches a peak as the majority of the antigen has been eliminated. The response then slowly declines, but is maintained at a high level relative to the peak response. The relative differences in the resulting memory $\mathrm{T}$ cell phenotype is inserted between the lines with color coding identifying the two populations.

\subsection{Tissue transduction properties}

The key to untangle these conflicting reports regarding the immunological properties of adenovirus vectors may lie in a better understanding of the mechanisms underlying the remarkable immunogenicity of adenoviral vectors and its relationship to route, dose and antigen presentation. To aid in this understanding we will first consider the unusual features of the adenoviral gene delivery system. Adenoviral vectors are not unique in their ability to target relevant populations of antigen presenting cells (Lindsay et al., 2010), but uniquely among all vaccine delivery technologies, adenoviral vectors have also received serious attention as vehicles of correctional or experimental gene therapy. Thus, adenoviral vectors can be used to transduce a large number of cell types, and intravenous or intramuscular application can lead to a situation where most liver cells or cells of the infected muscle are expressing vast amount of the transgene (Antinozzi et al., 1999; Jimenez-Chillaron et al., 1999; Okuyama et al., 1998). Thus, with the ability to transduce both professional APCs and vast numbers of tissue resident cells, adenoviruses are 
perfectly equipped to induce combined direct and cross-presentation of antigen to CD8+ $\mathrm{T}$ cells. In agreement with this notion, ubiquitous, keratinocyte specific and alveolar epithelial cell specific promoters have been used to induce CD8+ T cell responses towards the encoded antigen, and remarkably, no differences in the response level have been observed provided the administration route targeted cells with the relevant promoter activity (Prasad et al., 2001). Paradoxically, adenoviruses are extremely potent inducers of CD8+ $\mathrm{T}$ cells directed against the inserted transgene, yet induce levels of CD4+ $\mathrm{T}$ cell activation similar to that of naked DNA vaccines, which are much less efficient in tissue transduction (Wu et al., 2005). This is surprising because the ability to cross-prime CD8+ T cells implies that substantial amount of antigen are being released from dying cells, and this antigen would normally be expected to represent a good sources of peptides for MHC class II restricted presentation to CD4+ $\mathrm{T}$ cells. The reasons for this limited ability to induce CD4+ $\mathrm{T}$ cell responses are currently not understood. Unfortunately the study employing cell type specific promoters for antigen expression did not contain any data relating to the immunological potency, the kinetics of the response or the phenotype of the CD8+ T cells induced. This means, that while it is likely that both direct and crosspresentation contribute in the induction of the response, it has until recently been unclear what is the relative contribution of each type of antigen presentation pathway, how this contribution may differ between different antigens and how this may affect the phenotypes of the responding T cells. Recent work by our group (Holst et al., 2010b) and the group of Jonathan L. Bramson (Bassett et al., 2011; Finn et al., 2009; Yang et al., 2006) has now begun to address this issue in greater detail.

\subsection{The issue of dose}

Initially we discovered that increasing the dose of s.c. administered adenovirus from $10^{9}$ to $10^{10}$ or $10^{11}$ particles, caused most of the increased inoculum to enter the systemic circulation and transduce the cells of the liver and spleen at levels comparable to those found after an i.v. administration (Holst et al., 2010b) (see figure 3). Intravenous administration was found to induce a slow response and require more vector for initiating a transgene specific response (1010 particles i.v., while $10^{9}$ or less sufficed for s.c. administration). This is consistent with the notion that a key to a potent immune response is efficient priming in the local environment of the lymph nodes draining the injection site, and we were able to substantiate this suggestion by observing markedly impaired responses in L-selectin deficient mice after peripheral immunization using a moderate dose of adenovirus vectored vaccine (Holst PJ, Thomsen AR and Christensen JP, unpublished) (see figure 4A). However, after a considerable delay, i.v. administered adenovirus did induce a transgene specific CD8+ T cell response, which eventually surpassed the response following s.c. immunization in terms of cell numbers generated. For both routes of virus administration we found a positive correlation between the amount of vector reaching the systemic circulation and the magnitude of the response, whereas an inverse correlation was noted with regard to the quality of the response as measured by cytokine producing competence. These observations led us to suggest that dissemination of the vector was responsible for the apparent reduction in $\mathrm{T}$ cell quality in i.v. immunized mice. Bramson and co-workers had early on demonstrated that transgene expression after injection of moderate virus doses intramuscularly (i.m.) in the thigh were confined to the injection site and the draining lymph nodes (Yang et al., 2003). Recently, they took the mechanistic unraveling an important step 
further and demonstrated by surgical removal of the nodes that the full response depended on intact draining lymph nodes for more than 7 days post infection, but after 20 days they were no longer required. These results by themselves could have been an artifact reflecting the removal of antigen-specific CD8 $+\mathrm{T}$ cells sequestered in the draining lymph nodes rather than the abrogation of antigen presentation; yet they are consistent with the conclusions we drew from our experiments with L-selectin deficient mice. However, even in "denoded" mice, there was continuous $\mathrm{T}$ cell expansion for an additional 3 weeks, which could be abrogated by eliminating transcription of the transgene encoding gene using a doxycycline repressible system (Finn et al., 2009). This was interpreted by the authors to suggest that i.m. inoculation of adenovirus leads to extra nodal, but transgene expression dependent prolonged $\mathrm{T}$ cell expansion. To address this issue in detail they generated bone-marrow chimeric mice in which bone marrow cells from mice lacking the MHC element restricting the relevant transgene derived epitope was used for reconstitution of lethally irradiated WT mice. Using this system, they could confirm that epitopes restricted by MHC molecules only expressed by non-hematopoietic cells were driving late $\mathrm{T}$ cell expansion. This result was taken as evidence for non-hematopoietic antigen presentation by Bramson and co-workers and is referred to as such in the following; however, that this is the case has not been formally proven. Antigen could still be presented by professional antigen presenting cells which have acquired already peptide loaded MHC class I molecules from the surface of tissue resident, non-hematopoietic cells, a phenomenon coined by the phrase "crossdressing" (see figure 4C) (Dolan et al., 2006). Nevertheless, the T cells maintained exclusively by so-called non-hematopoietic antigen presentation showed marked deficiencies in particular with respect to cytokine production, but also featured a more pronounced effector memory surface phenotype as compared with $\mathrm{T}$ cells generated in context of both hematopoietic and non-hematopoietic antigen-presentation. These phenotypic differences were roughly identical to those we had previously observed when comparing responses elicited by i.v. administration with those elicited by s.c. administration. Importantly, the dysfunctional $\mathrm{T}$ cells, be they induced by i.v immunization or non-hematopoietic priming were quite capable of performing cytotoxic activity. We also found i.v. primed $\mathrm{T}$ cells to be efficient in protection against vaccinia challenge (Holst et al., 2010b), whereas Bramson and co-workers found that non-hematopoietic primed T cells were partially effective against LCMV or melanoma (Bassett et al., 2011). Importantly, we also found the $\mathrm{T}$ cells induced by i.v. administration to be less capable of secondary expansion (Holst et al., 2010b), whereas Bramson and co-workers found non-hematopoietic and hematopoietic priming equally efficient in inducing memory $\mathrm{T}$ cells capable of undergoing secondary expansion (Bassett et al., 2011). However, the secondary expansion and protection data reported by Bramson and co-workers requires careful evaluation. The experiments were performed in vaccinated chimeras with and without hematopoietic antigen presentation of the relevant epitopes, and thus the adenovirus induced $\mathrm{T}$ cell priming as well as the antigen presentation taking place during the challenge phase would be affected. This might not be important during melanoma challenge, but certainly would impact the effector phase of the responses to infections with rapidly replicating viruses such as LCMV, vaccinia virus or influenza. Furthermore, as the capacity for protection was evaluated through the challenge of intact animals rather than by adoptive transfers of primed donor cells into naïve hosts, we do not know the phenotype of the cells actually responding. Importantly, during early primary expansion of OVA specific $\mathrm{T}$ cells 
hematopoietic and non-hematopoietic antigen presentation worked synergistically to increase CD8 $+\mathrm{T}$ cell numbers, but only hematopoietic antigen presentation supported sustained functionality as measured by cytokine competence (Bassett et al., 2011). Notably, beyond 20 days post vaccination only extra-nodal expansion contributed to the $\mathrm{T}$ cell response. This method of antigen presentation is highly important during the early memory phase of the response as cessation of antigen expression by a doxycycline regulated vector drastically reduced the magnitude of late memory responses (Finn et al., 2009). Our tools did not allow detailed control of antigen expression, but we also observed a continuous expansion of memory $\mathrm{T}$ cells from 20 to 60 days post vaccination following high-dose i.v. adenovirus vector administration (Holst et al., 2010b).

\subsection{Model for adenovirus induced CD8+ T cell responses}

Although there are differences between the studies of Bramson and coworkers using doxycycline repressible presentation of the ovalbumine derived SIINFEKL epitope and our own using adenovirus encoded $\beta$-galactosidase, in particular with regard to the kinetics of the induced response, the conclusions drawn in these reports are consistent. Taken together, these studies allows us to propose a mechanism by which adenoviral vector delivered antigen primes an immune response in part by directly transducing the available tissue resident dendritic cells and in part by transduction of the local tissue resident, nonhematopoietic cells. Regarding the antigen produced by cells at the injection site this may either be cross-presented via hematopoietic dendritic cells expressing the same MHC molecules as the tissue cells, be presented by the novel mechanism of "cross-dressing" described in Bassett et al.(Bassett et al., 2011), or be directly presented to the CD8+ T cells in situ (see figure 4 for a complete description of the different mechanisms potentially involved in the presentation of antigen). Increasing the inoculum leads to the systemic dissemination of viral vector and an altered balance between dendritic cell mediated lymph node presentation and presentation mediated by non-hematopoietic cells independent of the draining lymph nodes (see figure 3 for a description of the interrelation between virus dose and site of antigen presentation). This in turn leads to poorer cytokine producing competence. The relative importance of hematopoietic and non-hematopoietic antigen presentation at doses below $\sim 10^{9}$ particles is as yet undetermined, but some studies in mice and primates as well as humans have demonstrated the relative stability of the response within 10- fold variations of the inoculum (Bassett et al., 2011; Bett et al., 2010), and we have seen a plateau of the response between $\sim 10^{9}$ to $\sim 10^{8}$ particles administered s.c., with a gradual reduction of the magnitude of the response upon further dose reductions (Holst PJ, Thomsen AR and Christensen JP, unpublished and (Flatz et al., 2010)). A possible explanation for these plateaus could be that these doses are sufficient to target all the relevant professional antigen presenting cells present at the injection site, and that the major difference between the doses are in the degree of non-dendritic cell targeted transduction. As the non professional APC transduction leads to poorer cytokine producing competence and generation of more terminally differentiated cells, it is worth noticing that we have observed an increase in the ratio of CD127high cells compared to KLRG1 high cells as the dose was further decreased (Holst PJ, Thomsen AR and Christensen JP, unpublished), and that termination of transgene expression after the acute response led to higher frequencies of central memory $\mathrm{T}$ cells, and higher CD27 expression, and a lower frequency of KLRG1 expression on the responding $\mathrm{T}$ cells (Finn et al., 2009). 


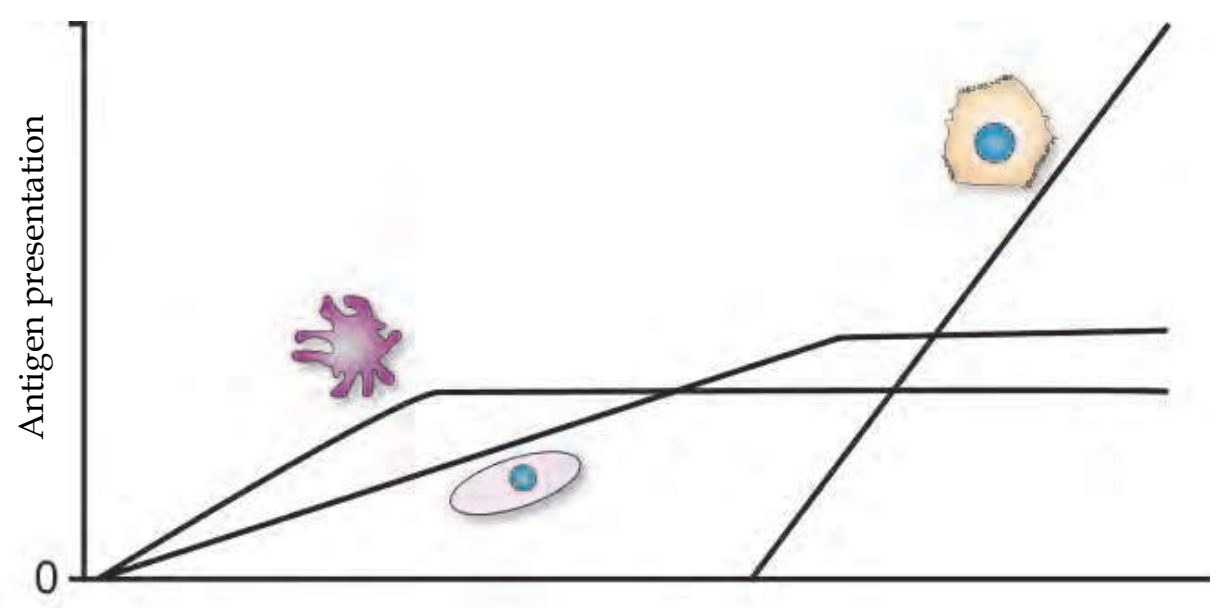

Vector dose

Fig. 3. Relative contribution of antigen presentation from different cell types driving the CD8+ $T$ cell expansion after peripheral administration of adenoviral vaccines. Injection of increasing amounts of adenoviral vaccine initially results in a gradual and dose-dependent increase in the transduction of professional antigen presenting cells (APC, represented by a ruffled cell placed above the line to the left) and tissue resident parenchymal cells (represented by an oval cell placed below the line). The peak level of APC transduction is reached at a lower dose than is the parenchymal cell transduction and thus the ratio of APC to parenchymal cell transduction gradually declines. Increasing the dose further leads to spill-over into the systemic circulation causing transduction of central organs, particularly the liver (represented by a hepatocyte inserted next to the line at the top right corner).

The differences between the response patterns observed by us and by Bramson and coworkers deserve some consideration. Most remarkably, we find i.v. administration of $10^{10}$ particles $\left(\sim 2 \times 10^{8} \mathrm{IFU}\right)$ of adenovirus to induce a response that becomes detectable in the spleen as late as between 30 and 60 days post vaccination whereas lower doses of virus given i.v. fail to induce any detectable response. Subcutaneous immunization induces an earlier response at lower doses. Bramson and co-workers on the other hand detect a response in the blood and spleen at 10 to 20 days post i.m. immunization with $10^{7}-10^{8}$ pfu of adenovirus encoding SIINFEKL fused to luciferase (Bassett et al., 2011; Finn et al., 2009). This difference in the kinetics of the response after i.v. as compared to i.m. administration is not likely to be due to differences in antigen as Flatz et al.(Flatz et al., 2010) also noted a profound attenuation of the response after intravenously administration of $2.5 \times 10^{8} \mathrm{pfu}$ of adenovirus encoding the SIINFEKL containing ovalbumin sequence, whereas a potent response was observed at lower doses, all measured at 28 days post vaccination. Thus, whereas the difference between our report and the one of Flatz et al. (Flatz et al., 2010), who observed a strong response to low doses of ovalbumin encoding adenovirus, are likely due to the immunological potency of the encoded antigen (ovalbumin being a potent antigen, while $\beta$-galactosidase is a weak antigen), the differences between Flatz and Bramson must relate to the route of administration. In this regard it is interesting that we observed an early, transient cytokine competent CD8+ T cell response in the liver following i.v. administration; 
this response seem to be associated with the transduction of liver cells, and it disappears before the systemic response can be measured in the spleen. The most likely explanation for this phenomenon is that the early transgene-specific $\mathrm{T}$ cell response is aborted within the liver parenchyma as previously reported for the adenovirus-specific response following i.v. immunization (Liu et al., 2001), and that systemic T-cell expansion can only occur after a reduction in transgene expression in the liver or when a lower inoculum has been used to induce the response as seen by Flatz et al.(Flatz et al., 2010). Based on our findings that peripheral virus administration leads to a marked increase in hepatic transduction when the dose is increased from $10^{9}$ to $10^{10}$ particles, and that the entire increase in dose at $10^{11}$ particles enters the systemic circulation, we would think that working with peripheral administration of adenovirus at doses above $10^{9}$ particles in murine systems entails a major risk for variability in response magnitude, kinetics and quality. The report from Tatsis et al.(Tatsis et al., 2007a) can be seen to support this conclusion as i.v. administration of $10^{10}$ adenoviral particles expressing LCMV glycoprotein gave a result midway between our results with i.v. administered $\beta$-gal at $10^{10}$ and s.c. administered $\beta$-gal at $10^{11}$ particles, whereas $10^{11}$ particles given i.m. induced a biphasic response. Hypothetically, the elimination of the first phase could be due to intrahepatic sequestration.

The delineation of adenovirus induced immune responses in hematopoietic and nonhematopoietic is recent, and the mechanisms of the non-hematopoietic antigen presentation is unknown. However, although non-hematopoietic antigen presentation is a novel finding for adenovirus induced immunizations, it is not the only system in which it is described. Thus, during allogenic bone marrow transplantation, non-hematopoietic antigen presentation contributes both to induction of $\mathrm{T}$ cells incapable of recall responses and functional exhaustion of T cells already generated (Flutter et al., 2010). What is special about the adenoviral immunization after a low dose injection is that it is taking place at a defined site and should in theory by highly amendable for studying. In any case, more attention should now be directed towards the events taking place at the site of adenovirus inoculation, because these appear to be crucial for both the immunological potency of adenoviral vectors and for excessive differentiation of adenovirus primed CD8+ effector T cells.

For non-hematopoietic antigen presentation to occur one must assume that either a local environment capable of causing naïve $T$ cells activation is induced by the interaction of the immune system and persisting antigen, or that the antigen is transported to secondary lymphoid organs by macrophages or dendritic cells cross-dressed with loaded peptide/MHC complexes derived from dying (?) cells within the infected tissue (see figure 4 for an overview of potential mechanisms). Potentially, cross-dressing of APCs at the injection site could occur either through capture of exosomes by dendritic cells (Utsugi-Kobukai et al., 2003) or through a cell-contact dependent mechanism (Dolan et al., 2006), although it should be noted that recent studies have questioned the ability of exosomes to contribute to relevant responses against viral infections in vivo. However, in the latter case the antigens tested have been different and the sensitivity of the assays may have been rather low (Coppieters et al., 2009). That expression of foreign antigen following adenoviral vector injection contributes to an inflammatory infiltrate seems beyond question as no long term infiltrate can be seen following injection with vectors devoid of viral genes and a transgene which does not prime an immune response (Chen et al., 1997), yet the interest in such infiltrates have focused on their ability to clear gene therapy vectors rather than on their role in supporting immune responses. Thus, at 
present, we know the infiltrates contain CD4+ and CD8+ T cells, few macrophages but little else. In other systems, chronic or extended inflammation has been seen to induce lymphoid like structures within parenchymatous organs such as the CNS, kidneys (Moskophidis et al., 1987) and bronchi (Moyron-Quiroz et al., 2004), and such changes could possibly also take place following adenovirus immunizations. A more thorough understanding of the events occurring at the injection site could perhaps lead to strategies impeding excessive $\mathrm{T}$ cell differentiation without removing antigen stimulation and thus result in generation of even more potent vaccines.
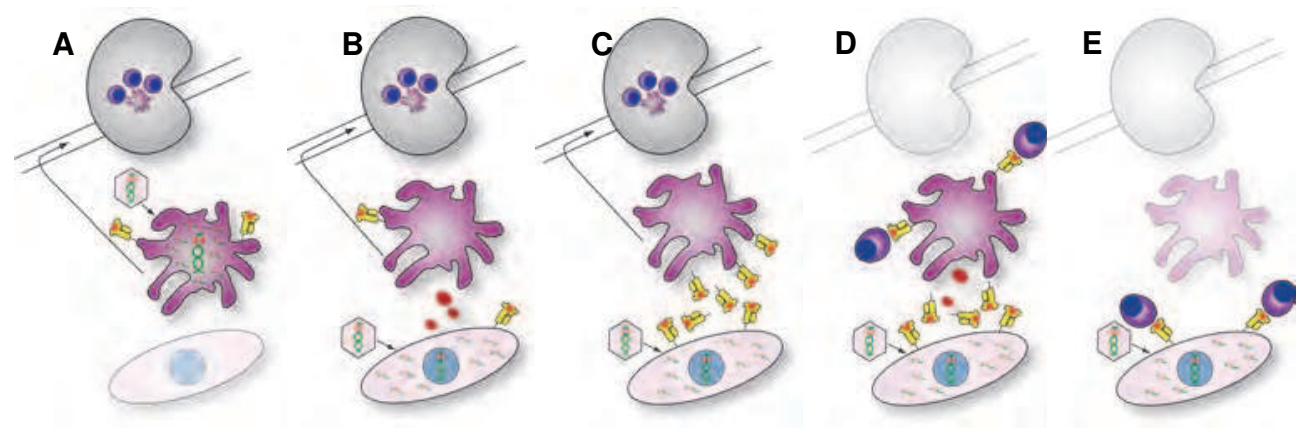

Fig. 4. Overview of the potential antigen presentation mechanisms after adenoviral vaccination. All the cartoons feature an oval tissue resident parenchymal cell in the bottom, a ruffled professional antigen presenting cell in the middle and a lymph node with afferent lymphatic vessels to the left. CD8+ T cells are drawn with a dark blue nuclei and dark purple cytoplasm. MHC class I molecules are yellow, whereas the presented recombinant antigen is red. Replication incompetent vectors are hexagonal containing double stranded DNA. A) Direct presentation. Professional APCs are directly transduced by the adenoviral vector, migrate to the draining lymph nodes and presents antigen synthesized within themselves to the CD8+ T cells. B) Cross-presentation. Tissue resident parenchymal cells are transduced and professional APCs take up the antigen, process it, migrate to the draining lymph node and on their own MHC molecules present the antigen to the CD8+ T cells. C) Cross-dressing. Tissue resident cell process and initially presents the antigen. However, somehow MHC/peptide complexes are released and taken up by APCs, which migrate to the draining lymph node and present the antigen to the CD8+ T cells on MHC molecules synthesized within the parenchymal cells. D) Local presentation by APCs. Tissue resident cells are transduced, but the antigen remains at the injection site. Resident and inflammatory APCs present antigen to CD8+ T cells locally, either from processing of tissue debris or from presentation of MHC molecules already loaded with antigen in the parenchymal cells. E) Local presentation without APC's. Tissue resident parenchymal cells are transduced, process the antigen and present it to CD8+ T cells locally on their own MHC class I molecules.

\subsection{The issue of quality}

The proposed model has profound implications for interpreting the existing literature and in appreciating the potential potency of adenoviral vectors for vaccination use. First of all, it partially explains why functionally exhausted $\mathrm{T}$ cells are a feature of increasing the dose beyond $10^{9}$ particles (in mice). Secondly, as chronic non-hematopoietic antigen presentation 
cannot be avoided, it may also help explain why adenovirus induced CD8+ T cells tend to be more terminally differentiated than are $\mathrm{T}$ cells induced by live viral vaccines or MVA vectors. As murine studies reporting an exhausted phenotype of adenovirus induced CD8+ $\mathrm{T}$ cells have typically involved virus doses in the range of 1010-1011 viral particles (Tatsis et al., 2007a; Yang et al., 2006), one might question the relevance of the results obtained when it comes to human or primate vaccination, where the virus dose is typically in the order of 1010-1011 particles (Bett et al., 2010). In contrast to the studies using high doses of adenoviral vectors in mice, CD8+ T cells induced by adenoviral vaccination in primates and humans are cytokine competent and cytotoxic cells, but seemingly terminally differentiated effectorlike cells are found in the circulation for extended periods of time. A key question in this respect is whether this should be of significant concern. In the opinion of these authors it should not. Under the premise that the adenoviral infection is not overdosed, the phenotype of adenovirus primed CD8 $+\mathrm{T}$ cells resemble that of $\mathrm{T}$ cells found in association with chronic, but well-controlled viral infections such as Epstein Barr virus infection in human (Ibegbu et al., 2005) and $\gamma$ herpes virus-68 (MHV-68) infection in mice (Cush \& Flano, 2011). A key cell surface marker in this context is KLRG1, the expression of which is often taken to indicate replicative senescence. However, in EBV infected humans it has been found that while KLRG1 is indeed expressed by terminally differentiated $\mathrm{T}$ cells, by no means all KLRG1high cells are end cells, but rather seem to represent a subset of memory cells associated with antigen persistence (Ibegbu et al., 2005). Along the same lines the meticulous study by Cush and Flãno (Cush \& Flano, 2011) have clearly demonstrated that KLRG1 high CD8+ T cells in MHV-68 infected mice are fully functional, can expand upon reactivation and provide even better protection against reinfection than do KLRG-1 ${ }^{\text {low }}$ cells with the same specificity. Furthermore, despite having predominantly an effector memory (CD62LlowCD43low) phenotype, KLRG1high CD8+ $\mathrm{T}$ cells may express receptors for homeostatic cytokines (IL-7 and IL-15) and can survive long-term in the absence of cognate antigen. Thus, although expression of KLRG1 may be associated with a decreasing potential for expansion, there are numerous observations indicating that these cells may be protective, and by way of their immediate effector capacity in fact could represent the most optimal type of vaccine-induced T-cell defence despite some limitations in proliferative capacity (Bachmann et al., 2005). An earlier study by the group of Rafi Ahmed investigating the responsiveness of mice undergoing repeated antigenic stimulation supports this view (Masopust et al., 2006). These authors found that increasing the number of antigenic challenges preferentially promoted the generation phenotypically similar memory cells that retained effector-like properties and showed preferential accumulation in non-lymphoid organs. Notably, neither the adenovirus primed CD8+ T cells nor those driven by repeated antigenic stimulation express the inhibitory receptor PD-1 typical of dysfunctional $\mathrm{T}$ cells (Barber et al., 2006; Bassett et al., 2011; Masopust et al., 2006).

\section{Increasing the potency of adenovirus vectors}

\subsection{Improving antigen presentation}

Even though adenovirus vectored vaccines stand among the most potent vaccine platforms for induction of CD8 T cell responses, it is apparent that better vaccines are needed still. Be that in magnitude of the response, breadth or phenotype of the induced cells. It is clear that simply providing more vaccine or administering adenovirus multiple times provide minimal benefit compared to low dose immunization, at least with potent antigens, and 
while awaiting a deeper understanding of non-hematopoietic antigen presentation, the goal is to do more with less (vaccine). Our group, and others in close pursuit, therefore set out to identify the mechanisms that would be rate limiting for adenovirus induced immune responses. We had prior experiences with enhancing the immune responses to DNA vaccines by covalently linking an ER exported minimal epitope to $\beta-2$ microglobulin as described (Uger et al., 1999; Uger \& Barber, 1998), thereby presumably increasing the direct antigen presentation on DNA transduced cells (Bartholdy et al., 2003; Bartholdy et al., 2004). When the same antigen was cloned into an adenoviral vector and compared to full length LCMV glycoprotein, we saw an acceleration and augmentation of the response, and the transgene specific response which otherwise depended on CD4+ T cell help could now be induced in MHC class II deficient mice (Holst et al., 2007). We have since confirmed that the transgene works by loading the encoded antigen directly onto the MHC in a processing independent manner as TAP deficient cells transduced with adenoviral vectors expressing the $\beta-2$ microglobulin fused minimal epitope were fully competent in stimulating antigen specific T cells in vivo whereas an antigen expression system more potent in WT mice was not (Holst PJ and Bassi MR, unpublished).

\subsection{Increasing the breadth of the CD8+ T cell response}

We were surprised to find that the native LCMV glycoprotein induced a CD8+ $\mathrm{T}$ cell response which were severely limited in breadth and predominantly focused on the immunodominant GP33 epitope. In retrospect, the limited breadth of the induced response is perhaps not so surprising and tends to be a general draw-back of viral vectored vaccines. The vector backbone of adenoviruses, poxviruses and other systems encode many $\mathrm{T}$ cell epitopes which may compete with the transgene for the attention of the CD8+ $\mathrm{T}$ cells (Schirmbeck et al., 2008). In a search for adenovirus vaccine modifications which might lead to broader $\mathrm{T}$ cell responses, we decided to improve MHC class II restricted antigen presentation by covalently linking the encoded antigen to the MHC class II associated Invariant chain (Diebold et al., 2001; Holst et al., 2008; Rowe et al., 2006). Surprisingly, this strategy improved not only CD4+ T cell responses, but also the kinetics, breadth, magnitude and stability of the CD8+ T cell response via increased MHC class I presentation and independently of MHC class II (Holst et al., 2011). We have since then confirmed these findings with a variety of antigens and are able to conclude that the level of antigen presentation on the adenovirus transduced cell is a limiting factor with regard to the speed and breadth of CD8+ T cell responses (Hoegh-Petersen et al., 2009; Mikkelsen et al., 2011; Sorensen et al., 2009). Given the apparent dichotomy of fast hematopoietic and chronic nonhematopoietic antigen presentation in adenoviral vaccination, this is highly consistent with the hypothesis that the above described strategies work at least in part to increase the first wave of antigen presentation mediated by dendritic cells directly transduced by the vector (see figure 2). Remarkably, the CD8+ T cell response induced by adenoviral vaccination with this type of modified construct seem to have acquired a normal contraction phase and the CD8+ T cell response typically stabilizes at approximately $10 \%$ of the level of the peak response (see figure 1). Though augmentation of direct early presentation should lead to an accelerated response, it is unclear if this would also result in reduced late phase presentation thereby allowing the return to a nearly normal contraction pattern. One could speculate that increased MHC class I restricted antigen presentation, also in the tissue resident cells, would result in more efficient antigen elimination at these sites by the antigen-specific CD8+ $\mathrm{T}$ cells, but it is also possible that CD4+ $\mathrm{T}$ cells and MHC class II restricted antigen 
presentation by tissue resident cells could play a role. Thus, the more efficient early induction of CD4+ T cells by the MHC class II associated Invariant chain linked constructs combined with local production of interferon- $\gamma$, which could cause local MHC class II upregulation and antigen presentation, might together set the stage for $\mathrm{CD} 4+\mathrm{T}$ cell mediated antigen elimination.

\subsection{Role of CD4+ T cell help}

Interestingly, we also found that while ordinary adenovaccine primed CD8+ $\mathrm{T}$ cell responses were CD4+ T-cell help dependent, neither of the tethered constructs required CD4+ T cells for induction of a primary CD8+ T-cell response (Holst et al., 2007; Holst et al., 2011). However, as has previously been observed also with fully CD4+ T-cell helped CD8+ T cells, the functionality of the generated cells decreased faster in a CD4+ T-cell deficient environment (Sun et al., 2004). Still, however, we saw significant protection against a highdose viral challenge in MHC class II deficient mice at 2 months post vaccination, which matched that found in wild type mice vaccinated with an ordinary adenovirus vaccine (Holst et al., 2007; Holst et al., 2011). This ability of our improved vaccine to induce an efficient acute and prolonged CD8+ T cell response in the absence of CD4+ T cells have clear implications as regards certain states of clinical immunodeficiency. Thus, in bone-marrow transplant recipients herpes virus infections represent a serious clinical problem. However, as the CD8+ T-cell population in these patients recovers faster than the CD4+ $\mathrm{T}$ cell population (Berger et al., 2008), this type of vaccine could be used to curtail such infections until the CD4+ T-cell population is restored.

Although several strategies can increase the immune response resulting from DNA vaccination there are not many strategies that have been published to augment the response to adenovirus vectored vaccines (reviewed in Holst et al. 2010 (Holst et al., 2010a)). Whether this reflects that very few strategies have actually been tested or that they have not worked efficiently is a matter of speculation, but it is tempting to conclude that virus vectored vaccines contains sufficient pathogen- associated molecular patterns to substitute for many a cytokine co-administered with the vaccine. Exceptions to the general rule has been antigen linked to the herpes viral tegument protein VP22 and calreticulin, which have been tested in Sindbis virus replicon particles (Cheng et al., 2002) and vaccinia vectors (Hsieh et al., 2004), respectively, and the herpes viral glycoprotein $\mathrm{D}(\mathrm{gD})$, which has been tested using an adenoviral vector. Both VP22 and calreticulin are suggested to work by increasing antigen presentations, but the herpes viral glycoprotein D was postulated to work by competitive inhibition of the interaction between the herpes virus entry mediator (HVEM) and the B and $\mathrm{T}$ lymphocyte attenuator (BTLA) (Lasaro et al., 2008). Although herpes viral gD fused to antigen was convincingly showed to interact with HVEM, there were no experiments performed in animals or cells deficient in HVEM or BTLA, nor was antigen presentation measured following use of this strategy. Thus whether or not HVEM-BTLA interaction is important in the immune response to adenoviral vectors remains to be determined (see (Holst et al., 2010a) for a detailed comment on this study). The MHC class II associated invariant chain linked antigen concept was also tested as a DNA vaccine, and found to increase CD8+ T cell responses working both alone and as a primer for an adenoviral boost. Moreover, the MHC class II associated Invariant chain linked antigen concept was also beneficial when applied in the booster supporting the conclusion that increased direct presentation benefits adenovirus induced CD8+ $\mathrm{T}$ cell responses after the initial priming (Grujic et al., 2009). 


\section{Adenovirus vectored vaccines compared to other vaccine technologies}

\subsection{Adenovirus induces unusually potent and protective CD8+ T cell responses}

With regard to sheer potency of long term CD8+ $\mathrm{T}$ cell induction there are only a few reports challenging the supremacy of adenovirus vectors, and none of these have been verified in humans. In primates, adenoviral vectors have been tested side-by-side with MVA and DNA vectors and matched studies have been performed in humans (Bett et al., 2010; Casimiro et al., 2003; Shiver et al., 2002). These studies have unequivocally shown that adenoviral vectors induce superior frequencies of CD8+ $\mathrm{T}$ cells and, importantly, induce better $\mathrm{T}$ cell mediated protection against simian human immunodeficiency virus challenge (SHIV) in NHP's. However, other general findings include a low proliferative potential of induced $\mathrm{T}$ cells, effector memory rather than central memory phenotype of the induced $\mathrm{T}$ cells and a low frequency of IL-2 producing T cells (Tatsis et al., 2007a; Yang et al., 2006; Yang et al., 2007). Although several studies have addressed potency and immunogenicity of antigen presentation from various vectors, few direct comparisons exists between adenoviral vectors and other popular virus vectored vaccine candidates, most notably MVA and fowlpox vectors. A recent study has been made in mice comparing human adenovirus serotype 5, simian serotype C6, fowlpox vectors and MVA. These studies confirmed the tendencies reported above, but remarkably again demonstrated a superior protective efficacy of the adenoviral vector system. Thus, even though adenovirus vectors induce CD8+ T cells with functional and phenotypic properties most similar to those found in association with unresolved chronic infections, they still stand as superior vectors for $\mathrm{T}$ cell mediated protection against acute and chronic infections (Shiver et al., 2002; Sridhar et al., 2008). A paradox which has caused confusion, but in the opinion of these authors, a paradox which can be easily be appreciated if one considers the impact of the acute phase of an infection as a major determinant of the course of the chronic phase of an infection. Also, the negative result of the STEP trial regarding clinical protection against HIV may have attracted much too negative attention to the adenoviral vector system. Recent follow- up data of infected vaccinees revealed that the infecting HIV strains have accumulated mutations matching the most immunogenic epitopes of the vaccine, thus demonstrating that the adenovirus vectored vaccine has exerted an efficient selection pressure upon the infecting virus (Rolland et al., 2011). In conclusion, the vaccine induced T cells did work, but as the vaccine induced T-cell responses were rather narrowly targeted and raised against $\mathrm{T}$ cell epitopes that can readily be mutated, the induced response simply was not sufficient to permanently control infection with a rapidly mutating virus like HIV. Some improvement strategies to the immunogenicity of the adenovirus vaccines have been discussed above (see the "Increasing the potency of adenovirus vectors" section above), whereas the most commonly applied strategy, prime-boost regimens will be discussed below.

\subsection{Adenovirus induced antibody responses}

Although the major focus of this review is on adenovirus induced $\mathrm{T}$ cell responses, it should be noted that the benefits of adenoviral vectors for induction of antibody responses is less clear. It is noteworthy that adenoviral vectors, despite their capacity for induction of high titers of antibodies, may fall short of MVA vectors when it comes to induction of crossreacting antibodies against influenza and SIV. Thus, MVA vectors expressing the hemagglutinin antigen of influenza A H5N1/Vietnam/2004 provide efficient cross-clade protection against H5N1/Indonesia/2005 challenge in primates (Kreijtz et al., 2009), 
whereas similar adenovirus vectors appear less potent, and infectious virus may still be detectable after homologous challenge (Gao et al., 2006). Direct comparisons are lacking. Similarly, in the SHIV system, Robinson and colleagues have developed a DNA and MVA based vaccine which uses the large cloning capacity of the poxvirus vector to simultaneously encode gp41 and gag and thus produce virus-like particles. Highly avid antibodies to native gp41 appear to constitute a correlate of protection against peak viremia which transcends into improved control in the chronic phase of the infection (Zhao et al., 2009). Again, a similar strategy has not been tested with adenovirus vectors. Thus, there is suggestive evidence that MVA vectors are superior or at least as potent as adenovirus vectors with respect to induction of broadly reactive antibodies. Why adenovirus vectors induce superior CD8+ $\mathrm{T}$ cell responses, but only comparable antibody responses has not been systematically addressed. However, as vectors such as the MVA induce their associated immune response in considerable less time than do the adenoviral vectors, the former could be speculated to rely on the recruitment of more B cell precursors to reach the same levels as the adenovirus vectored vaccines and therefore induce more diverse responses.

\section{Use of adenovirus vaccines in prime-boost regimens}

\subsection{Use of adenovirus in heterologous prime-boost regimens}

Pre-clinically, adenovirus vectors have been used rather successful as boosters for DNA immunizations, and paradoxically as they potentially induce memory $\mathrm{T}$ cells with a restricted proliferative potential, also as primers for poxvirus booster immunizations. The use of DNA priming is logical and results in a broadening of the CD4+ T cell response, an increase in the IL-2 competence of the primed CD8+ T cells and improved protection after SIV challenge (Casimiro et al., 2005; Cox et al., 2008; Wu et al., 2005). Please note that although some animal studies point to an improved immunogenicity of DNA primed adenovirus immunizations (Grujic et al., 2009), this has not been verified in humans (Bett et al., 2010). Although DNA primed adenovirus immunization have shown some promise, it pales in comparison to the recent pre-clinical results obtained using adenoviruses of different serotypes (Liu et al., 2009) or adenovirus as primers for MVA vectors (ReyesSandoval et al., 2010). The use of such prime-boost regimens have improved the protective efficacy against SIV or rodent malaria compared to the use of either vector system alone, although it should be stressed that the reason for the improved protection is unclear. The heterologous adenovirus based immunization by Barouch and co-workers induced increased CD4+ $\mathrm{T}$ cell responses and CD8 $+\mathrm{T}$ cells of increased functionality, but the correlate of protection was with the breadth of the response (Liu et al., 2009). Similar phenotypic changes were seen in a rodent malaria model, yet here protection was correlated with the total numbers of IFN- $\gamma$ producing CD8+ T cells (Reyes-Sandoval et al., 2010). As noted above, all these data strongly suggest that the $\mathrm{T}$ cells induced by adenoviral immunization are at least acutely protective. Notably, by documenting the ability of adenoviral vectors to prime for subsequent responses, these observations also questions the notion that adenovirus induced $\mathrm{T}$ cells necessarily have a limited proliferative capacity. Not only vaccines can boost adenovirus primed responses, also live LCMV infection in mice (Holst et al., 2011) or SIV in primates (Liu et al., 2009; Sun et al., 2008) cause massive postexposure expansion of adenovirus primed T cells. In this context it is noteworthy that direct analysis of the adenovirus primed T cells' ability to proliferate have mostly been performed 
following what seems likely to be represent inoculation of unreasonably high doses of virus (see above for details), and the obtained results may therefore not be very relevant to a more real-life vaccine situation. An additional factor explaining the discrepancy may be that ex vivo analysis of proliferative capacity is typically performed on either blood or spleen cells, whereas an infection or an immunization can boost any $\mathrm{T}$ cell population present in the challenged animal. The phenotype and tissue localization of $\mathrm{T}$ cells responding with proliferation in response to a secondary immunization or challenge infection remains unknown, and the most relevant cells may not be present in blood or spleen in significant quantities.

\subsection{Heterologous prime-boost regimens impact $T$ cell quality}

The study of Barouch and co-workers revealed an impact of the particular adenoviral serotype used for priming, on the phenotype and functionality of the ensuing $\mathrm{T}$ cell response, and suggested that special rare serotypes may have unique properties (Liu et al., 2008). However, as noted above, the heterologous prime-boost regimens in rodents using malaria antigens also reported an increased functionality of the induced CD8+ $\mathrm{T}$ cells (Reyes-Sandoval et al., 2010). An interesting observation in this regard was made when a triple sequential immunization was attempted using two different serotype of adenoviral vectors together with MVA. The third immunization induced further expansion of the CD8+ $\mathrm{T}$ cell response, increased their tissue homing and increased their cytokine producing competence (Tatsis et al., 2007b). Whereas expansion and increases in tissue homing capacity may be general phenomena following sequential immunization and has been seen in other systems as well as (Masopust et al., 2006), the increase in cytokine producing competence following the third immunization is harder to explain and has not been investigated. However, it is possible that the very strong response of transgene specific tissue homing CD8+ $\mathrm{T}$ cell may contribute to a rapid reduction of tissue localized vector, which would be in line with the notion that this pool of antigen contributes to induce CD8+ $\mathrm{T}$ cells of low cytokine producing competence.

\section{Disease indications where the attributes of adenoviral vectored vaccines are especially useful}

In principle adenoviral vectors would be useful wherever a strong and sustained antibody and/or CD8+ $\mathrm{T}$ cell response is readily inducible and contributing to protection. Acute infections such as avian influenza (Gao et al., 2006), Ebola (Richardson et al., 2009; Sullivan et al., 2003), foot-and-mouth disease virus (Pacheco et al., 2005) and rabies (Hu et al., 2006) are prime examples, but the list of published pre-clinical infections with high efficacy of adenovirus based vaccines essentially goes on and on. However, the more challenging vaccine targets are undoubtedly those involving infections with a propensity to become chronic such as HIV, HCV and the herpesviruses, or those where antibody inducing immunization may potentially exacerbate disease, such as dengue virus. These viruses have in common that sufficiently broad, high-titered and stable antibodies cannot readily be induced and that $\mathrm{T}$ cells therefore are needed to do the job. Accordingly, fairly solid preclinical data using adenoviral vectors have been obtained in the SIV model system (Liu et al., 2009) and the chimpanzee model of HCV infection (Folgori et al., 2006). However, the scientific community is still debating how to improve this further and develop clinically useful vaccines. In this review we would offer a different opinion from that of the majority 
regarding such diseases. Thus, while the focus have been on inducing immune responses capable of persisting during chronic infections, it is worth remembering that no actual intervention strategy succeeding in contributing to chronic virus control have done so without first reducing acute viral replication. An interesting case in this context is the SIV model for HIV infection. In this system, rapid application of highly active anti-retroviral therapy can lead to complete control of the virus and even protection against rechallenge (Lifson et al., 2001). This suggests that the rapidity of early virus control should be the goal for vaccine development. Another case supporting this suggestion is found in the MHV-68 model. In this system, a potent adenovirus vectored vaccine capable of reducing the splenic viral load after 14 days, was unable to impact the level of the latent infection. However, local immunization using intranasal application of the vaccine resulted in enhanced acute control at 7 days after infection as well as in improved control of the latent infection (HoeghPetersen et al., 2009). The lesson for vaccine development seems to be that increased efficacy can be expected against different disease targets by ensuring that CD8+ T cells are present and efficient at the site of virus entry/early virus replication and, furthermore, that these cells can rapidly acquire effector functions and reduce the viral load. Regarding the phenotype associated with acute control, adenovirus vaccines induce CD8+ T cells that for extended periods of time can exert immediate cytotoxic activity whereas immediate effector functions are quite limited in the less differentiated central memory $\mathrm{T}$ cells that seem to accumulate during controlled SIV or HIV infection. Also, regarding the ability to apply vaccines in manners that will induce local immunosurveillance at the likely site of virus entry or early replication, adenoviral vaccines have been found to be very useful. Thus, studies have suggested that local application can be used to augment mucosal CD8+ T cell memory (Belyakov et al., 2008; de Souza et al., 2007; Kaufman et al., 2010; Lemiale et al., 2007), and also that parenteral immunization can be used to induce $\mathrm{T}$ cell homing to mucosal sites (Haut et al., 2010; Kaufman et al., 2010; Lin et al., 2007; Tatsis et al., 2007b). The ability to induce local $\mathrm{T}$ cell responses is not a quality unique to adenovirus vectors and local immunity can also be obtained by mucosal application of pox-viral vectors (Corbett et al., 2008). Unfortunately, direct comparisons of vector systems for induction of mucosal immune responses seem to be lacking. While it may seem encouraging that parenteral immunization induces efficient $\mathrm{T}$ cell memory at mucosal sites, it should be noted that the assays performed to document mucosal homing are typically performed using tissue fractions or whole tissue homogenates. When we attempted a clean sampling of CD8+ T cells patrolling the mucosal surface of the lungs and airways by harvesting the bronchioalveolar lavage (BAL), only minimal frequencies of antigen specific cells could be detected after s.c. immunization whereas robust responses were seen after a single intranasal immunization. It seems possibly that there may be a difference between inducing the migration of $\mathrm{T}$ cells into a tissue with a large mucosal surface and to actually make the cells dedicated with respect to patrolling this surface for infected cells. In support of a compartmentalized CD8 $+\mathrm{T}$ cell memory at mucosal organs, immune responses in the mesenteric lymph nodes, which are frequently interpreted as a sign of induction of mucosal immunity in the gut, are efficiently induced following i.m. adenoviral immunization (Kaufman et al., 2010; Lin et al., 2007), whereas genuine mucosal immunization does not increase $\mathrm{T}$ cell frequencies in this site (Belyakov et al., 2008). Fortunately, concomitant subcutaneous and intranasal administration can induce $\mathrm{T}$ cell memory at both mucosal (BAL) (Hoegh-Petersen et al., 2009) and systemic (spleen) sites (these authors and Mette Hoegh-Petersen, unpublished). 


\section{Future perspectives}

Apart from attempting to combat chronic infections prophylactically, the realization that adenovirus primes $\mathrm{T}$ cells for extended periods of time based on extra-nodal and perhaps even non-hematopoietic antigen presentation opens up an interesting avenue for further studies. Thus, as the understanding of extranodal priming increases, so will the ability to modulate it, for instance by co-encoding cytokines or inhibitors of immunomodulatory molecules. Adenovirus vectors could in this respect have unique qualities which could be exploited for therapeutic vaccines against cancer or chronic infection.

\section{Acknowledgements}

The authors wish to thank Grazyna Hahn Poulsen for making the layout of the figures.

\section{References}

Abbink P., Lemckert A.A., Ewald B.A., Lynch D.M., Denholtz M., Smits S., Holterman L., Damen I., Vogels R., Thorner A.R., O'Brien K.L., Carville A., Mansfield K.G., Goudsmit J., Havenga M.J. \& Barouch D.H. (2007). Comparative seroprevalence and immunogenicity of six rare serotype recombinant adenovirus vaccine vectors from subgroups B and D. J Virol Vol. 81, No. 9: pp. 4654-4663.

Alkhatib G. \& Briedis D.J. (1988). High-level eucaryotic in vivo expression of biologically active measles virus hemagglutinin by using an adenovirus type 5 helper-free vector system. J Virol Vol. 62, No. 8: pp. 2718-2727.

Antinozzi P.A., Berman H.K., O'Doherty R.M. \& Newgard C.B. (1999). Metabolic engineering with recombinant adenoviruses. Annu Rev Nutr Vol. 19, No. 511-544.

Bachmann M.F., Wolint P., Schwarz K. \& Oxenius A. (2005). Recall proliferation potential of memory CD8+ T cells and antiviral protection. J Immunol Vol. 175, No. 7: pp. 46774685.

Barber D.L., Wherry E.J., Masopust D., Zhu B., Allison J.P., Sharpe A.H., Freeman G.J. \& Ahmed R. (2006). Restoring function in exhausted CD8 T cells during chronic viral infection. Nature Vol. 439, No. 7077: pp. 682-687.

Barefoot B., Thornburg N.J., Barouch D.H., Yu J.S., Sample C., Johnston R.E., Liao H.X., Kepler T.B., Haynes B.F. \& Ramsburg E. (2008). Comparison of multiple vaccine vectors in a single heterologous prime-boost trial. Vaccine Vol. 26, No. 48: pp. 61086118.

Bartholdy C., Stryhn A., Christensen J.P. \& Thomsen A.R. (2004). Single-epitope DNA vaccination prevents exhaustion and facilitates a broad antiviral CD8+ T cell response during chronic viral infection. J Immunol Vol. 173, No. 10: pp. 6284-6293.

Bartholdy C., Stryhn A., Hansen N.J., Buus S. \& Thomsen A.R. (2003). Incomplete effector/memory differentiation of antigen-primed CD8+ T cells in gene gun DNAvaccinated mice. Eur J Immunol Vol. 33, No. 7: pp. 1941-1948.

Bassett J.D., Yang T.C., Bernard D., Millar J.B., Swift S.L., McGray A.J., VanSeggelen H., Boudreau J.E., Finn J.D., Parsons R., Evelegh C., Damjanovic D., Grinshtein N., Divangahi M., Zhang L., Xing Z., Wan Y. \& Bramson J.L. (2011). CD8+ T-cell expansion and maintenance after recombinant adenovirus immunization rely upon 
cooperation between hematopoietic and nonhematopoietic antigen-presenting cells. Blood Vol. 117, No. 4: pp. 1146-1155.

Belyakov I.M., Ahlers J.D., Nabel G.J., Moss B. \& Berzofsky J.A. (2008). Generation of functionally active HIV-1 specific CD8+ CTL in intestinal mucosa following mucosal, systemic or mixed prime-boost immunization. Virology Vol. 381, No. 1: pp. 106-115.

Benlahrech A., Harris J., Meiser A., Papagatsias T., Hornig J., Hayes P., Lieber A., Athanasopoulos T., Bachy V., Csomor E., Daniels R., Fisher K., Gotch F., Seymour L., Logan K., Barbagallo R., Klavinskis L., Dickson G. \& Patterson S. (2009). Adenovirus vector vaccination induces expansion of memory CD4 T cells with a mucosal homing phenotype that are readily susceptible to HIV-1. Proc Natl Acad Sci U S A Vol. 106, No. 47: pp. 19940-19945.

Berger M., Figari O., Bruno B., Raiola A., Dominietto A., Fiorone M., Podesta M., Tedone E., Pozzi S., Fagioli F., Madon E. \& Bacigalupo A. (2008). Lymphocyte subsets recovery following allogeneic bone marrow transplantation (BMT): CD4+ cell count and transplant-related mortality. Bone Marrow Transplant Vol. 41, No. 1: pp. 55-62.

Bett A.J., Dubey S.A., Mehrotra D.V., Guan L., Long R., Anderson K., Collins K., Gaunt C., Fernandez R., Cole S., Meschino S., Tang A., Sun X., Gurunathan S., Tartaglia J., Robertson M.N., Shiver J.W. \& Casimiro D.R. (2010). Comparison of T cell immune responses induced by vectored HIV vaccines in non-human primates and humans. Vaccine Vol. 28, No. 50: pp. 7881-7889.

Buchbinder S.P., Mehrotra D.V., Duerr A., Fitzgerald D.W., Mogg R., Li D., Gilbert P.B., Lama J.R., Marmor M., Del R.C., McElrath M.J., Casimiro D.R., Gottesdiener K.M., Chodakewitz J.A., Corey L. \& Robertson M.N. (2008). Efficacy assessment of a cellmediated immunity HIV-1 vaccine (the Step Study): a double-blind, randomised, placebo-controlled, test-of-concept trial. Lancet Vol. 372, No. 9653: pp. 1881-1893.

Casimiro D.R., Chen L., Fu T.M., Evans R.K., Caulfield M.J., Davies M.E., Tang A., Chen M., Huang L., Harris V., Freed D.C., Wilson K.A., Dubey S., Zhu D.M., Nawrocki D., Mach H., Troutman R., Isopi L., Williams D., Hurni W., Xu Z., Smith J.G., Wang S., Liu X., Guan L., Long R., Trigona W., Heidecker G.J., Perry H.C., Persaud N., Toner T.J., Su Q., Liang X., Youil R., Chastain M., Bett A.J., Volkin D.B., Emini E.A. \& Shiver J.W. (2003). Comparative immunogenicity in rhesus monkeys of DNA plasmid, recombinant vaccinia virus, and replication-defective adenovirus vectors expressing a human immunodeficiency virus type 1 gag gene. J Virol Vol. 77, No. 11: pp. 6305-6313.

Casimiro D.R., Wang F., Schleif W.A., Liang X., Zhang Z.Q., Tobery T.W., Davies M.E., McDermott A.B., O'Connor D.H., Fridman A., Bagchi A., Tussey L.G., Bett A.J., Finnefrock A.C., Fu T.M., Tang A., Wilson K.A., Chen M., Perry H.C., Heidecker G.J., Freed D.C., Carella A., Punt K.S., Sykes K.J., Huang L., Ausensi V.I., Bachinsky M., Sadasivan-Nair U., Watkins D.I., Emini E.A. \& Shiver J.W. (2005). Attenuation of simian immunodeficiency virus SIVmac239 infection by prophylactic immunization with dna and recombinant adenoviral vaccine vectors expressing Gag. J Virol Vol. 79, No. 24: pp. 15547-15555.

Chen H.H., Mack L.M., Kelly R., Ontell M., Kochanek S. \& Clemens P.R. (1997). Persistence in muscle of an adenoviral vector that lacks all viral genes. Proc Natl Acad Sci U S A Vol. 94, No. 5: pp. 1645-1650. 
Cheng W.F., Hung C.F., Hsu K.F., Chai C.Y., He L., Polo J.M., Slater L.A., Ling M. \& Wu T.C. (2002). Cancer immunotherapy using Sindbis virus replicon particles encoding a VP22-antigen fusion. Hum Gene Ther Vol. 13, No. 4: pp. 553-568.

Coppieters K., Barral A.M., Juedes A., Wolfe T., Rodrigo E., Thery C., Amigorena S. \& von Herrath M.G. (2009). No significant CTL cross-priming by dendritic cell-derived exosomes during murine lymphocytic choriomeningitis virus infection. J Immunol Vol. 182, No. 4: pp. 2213-2220.

Corbett M., Bogers W.M., Heeney J.L., Gerber S., Genin C., Didierlaurent A., Oostermeijer H., Dubbes R., Braskamp G., Lerondel S., Gomez C.E., Esteban M., Wagner R., Kondova I., Mooij P., Balla-Jhagihoorsingh S., Beenhakker N., Koopman G., van der Burg S., Kraehenbuhl J.P. \& Le P.A. (2008). Aerosol immunization with NYVAC and MVA vectored vaccines is safe, simple, and immunogenic. Proc Natl Acad Sci $U$ $S$ A Vol. 105, No. 6: pp. 2046-2051.

Cox K.S., Clair J.H., Prokop M.T., Sykes K.J., Dubey S.A., Shiver J.W., Robertson M.N. \& Casimiro D.R. (2008). DNA gag/adenovirus type 5 (Ad5) gag and Ad5 gag/Ad5 gag vaccines induce distinct T-cell response profiles. J Virol Vol. 82, No. 16: pp. 8161-8171.

Cush S.S. \& Flano E. (2011). KLRG1+NKG2A+ CD8 T Cells Mediate Protection and Participate in Memory Responses during \{gamma\}-Herpesvirus Infection. $J$ Immunol Vol. 186, No. 7: pp. 4051-4058.

de Souza A.P., Haut L.H., Silva R., Ferreira S.I., Zanetti C.R., Ertl H.C. \& Pinto A.R. (2007). Genital CD8+ T cell response to HIV-1 gag in mice immunized by mucosal routes with a recombinant simian adenovirus. Vaccine Vol. 25, No. 1: pp. 109-116.

Diebold S.S., Cotten M., Koch N. \& Zenke M. (2001). MHC class II presentation of endogenously expressed antigens by transfected dendritic cells. Gene Ther Vol. 8, No. 6: pp. 487-493.

Dolan B.P., Gibbs K.D., Jr. \& Ostrand-Rosenberg S. (2006). Dendritic cells cross-dressed with peptide MHC class I complexes prime CD8+ T cells. J Immunol Vol. 177, No. 9: pp. 6018-6024.

Finn J.D., Bassett J., Millar J.B., Grinshtein N., Yang T.C., Parsons R., Evelegh C., Wan Y., Parks R.J. \& Bramson J.L. (2009). Persistence of transgene expression influences CD8+ T-cell expansion and maintenance following immunization with recombinant adenovirus. J Virol Vol. 83, No. 23: pp. 12027-12036.

Flatz L., Hegazy A.N., Bergthaler A., Verschoor A., Claus C., Fernandez M., Gattinoni L., Johnson S., Kreppel F., Kochanek S., Broek M., Radbruch A., Levy F., Lambert P.H., Siegrist C.A., Restifo N.P., Lohning M., Ochsenbein A.F., Nabel G.J. \& Pinschewer D.D. (2010). Development of replication-defective lymphocytic choriomeningitis virus vectors for the induction of potent CD8+ T cell immunity. Nat Med Vol. 16, No. 3: pp. 339-345.

Flutter B., Edwards N., Fallah-Arani F., Henderson S., Chai J.G., Sivakumaran S., Ghorashian S., Bennett C.L., Freeman G.J., Sykes M. \& Chakraverty R. (2010). Nonhematopoietic antigen blocks memory programming of alloreactive CD8+ T cells and drives their eventual exhaustion in mouse models of bone marrow transplantation. J Clin Invest Vol. 120, No. 11: pp. 3855-3868.

Folgori A., Capone S., Ruggeri L., Meola A., Sporeno E., Ercole B.B., Pezzanera M., Tafi R., Arcuri M., Fattori E., Lahm A., Luzzago A., Vitelli A., Colloca S., Cortese R. \& 
Nicosia A. (2006). A T-cell HCV vaccine eliciting effective immunity against heterologous virus challenge in chimpanzees. Nat Med Vol. 12, No. 2: pp. 190-197.

Gao W., Soloff A.C., Lu X., Montecalvo A., Nguyen D.C., Matsuoka Y., Robbins P.D., Swayne D.E., Donis R.O., Katz J.M., Barratt-Boyes S.M. \& Gambotto A. (2006). Protection of mice and poultry from lethal H5N1 avian influenza virus through adenovirus-based immunization. J Virol Vol. 80, No. 4: pp. 1959-1964.

Grujic M., Holst P.J., Christensen J.P. \& Thomsen A.R. (2009). Fusion of a viral antigen to invariant chain leads to augmented T-cell immunity and improved protection in gene-gun DNA-vaccinated mice. J Gen Virol Vol. 90, No. Pt 2: pp. 414-422.

Haut L.H., Lin S.W., Tatsis N., DiMenna L.J., Giles-Davis W., Pinto A.R. \& Ertl H.C. (2010). Robust genital gag-specific CD8+ T-cell responses in mice upon intramuscular immunization with simian adenoviral vectors expressing HIV-1-gag. Eur J Immunol Vol. 40, No. 12: pp. 3426-3438.

Hoegh-Petersen M., Thomsen A.R., Christensen J.P. \& Holst P.J. (2009). Mucosal immunization with recombinant adenoviral vectors expressing murine gammaherpesvirus-68 genes M2 and M3 can reduce latent viral load. Vaccine Vol. 27, No. 48: pp. 6723-6730.

Holst P.J., Bartholdy C., Stryhn A., Thomsen A.R. \& Christensen J.P. (2007). Rapid and sustained CD4+ T-cell-independent immunity from adenovirus-encoded vaccine antigens. J Gen Virol Vol. 88, No. Pt 6: pp. 1708-1716.

Holst P.J., Bassi M.R., Thomsen A.R. \& Christensen J.P. (2010a). DNA fusion gene vaccines. Curr Opin Mol Ther Vol. 12, No. 1: pp. 47-54.

Holst P.J., Christensen J.P. \& Thomsen A.R. (2011). Vaccination against Lymphocytic Choriomeningitis Virus Infection in MHC Class II-Deficient Mice. J Immunol Vol. 186, No. 7: pp. 3997-4007.

Holst P.J., Orskov C., Thomsen A.R. \& Christensen J.P. (2010b). Quality of the transgenespecific CD8+ $\mathrm{T}$ cell response induced by adenoviral vector immunization is critically influenced by virus dose and route of vaccination. J Immunol Vol. 184, No. 8: pp. 4431-4439.

Holst P.J., Sorensen M.R., Mandrup Jensen C.M., Orskov C., Thomsen A.R. \& Christensen J.P. (2008). MHC class II-associated invariant chain linkage of antigen dramatically improves cell-mediated immunity induced by adenovirus vaccines. J Immunol Vol. 180, No. 5: pp. 3339-3346.

Hsieh C.J., Kim T.W., Hung C.F., Juang J., Moniz M., Boyd D.A., He L., Chen P.J., Chen C.H. \& Wu T.C. (2004). Enhancement of vaccinia vaccine potency by linkage of tumor antigen gene to gene encoding calreticulin. Vaccine Vol. 22, No. 29-30: pp. 39934001.

Hu R., Zhang S., Fooks A.R., Yuan H., Liu Y., Li H., Tu C., Xia X. \& Xiao Y. (2006). Prevention of rabies virus infection in dogs by a recombinant canine adenovirus type-2 encoding the rabies virus glycoprotein. Microbes Infect Vol. 8, No. 4: pp. 1090-1097.

Ibegbu C.C., Xu Y.X., Harris W., Maggio D., Miller J.D. \& Kourtis A.P. (2005). Expression of killer cell lectin-like receptor G1 on antigen-specific human CD8+ T lymphocytes during active, latent, and resolved infection and its relation with CD57. J Immunol Vol. 174, No. 10: pp. 6088-6094. 
Jimenez-Chillaron J.C., Newgard C.B. \& Gomez-Foix A.M. (1999). Increased glucose disposal induced by adenovirus-mediated transfer of glucokinase to skeletal muscle in vivo. FASEB J Vol. 13, No. 15: pp. 2153-2160.

Kaufman D.R., Bivas-Benita M., Simmons N.L., Miller D. \& Barouch D.H. (2010). Route of adenovirus-based HIV-1 vaccine delivery impacts the phenotype and trafficking of vaccine-elicited CD8+ T lymphocytes. J Virol Vol. 84, No. 12: pp. 5986-5996.

Kreijtz J.H., Suezer Y., de M.G., van den Brand J.M., van A.G., Schnierle B.S., Kuiken T., Fouchier R.A., Lower J., Osterhaus A.D., Sutter G. \& Rimmelzwaan G.F. (2009). Recombinant modified vaccinia virus Ankara expressing the hemagglutinin gene confers protection against homologous and heterologous $\mathrm{H} 5 \mathrm{~N} 1$ influenza virus infections in macaques. J Infect Dis Vol. 199, No. 3: pp. 405-413.

Lasaro M.O., Tatsis N., Hensley S.E., Whitbeck J.C., Lin S.W., Rux J.J., Wherry E.J., Cohen G.H., Eisenberg R.J. \& Ertl H.C. (2008). Targeting of antigen to the herpesvirus entry mediator augments primary adaptive immune responses. Nat Med Vol. 14, No. 2: pp. 205-212.

Lemiale F., Haddada H., Nabel G.J., Brough D.E., King C.R. \& Gall J.G. (2007). Novel adenovirus vaccine vectors based on the enteric-tropic serotype 41. Vaccine Vol. 25, No. 11: pp. 2074-2084.

Lifson J.D., Rossio J.L., Piatak M., Jr., Parks T., Li L., Kiser R., Coalter V., Fisher B., Flynn B.M., Czajak S., Hirsch V.M., Reimann K.A., Schmitz J.E., Ghrayeb J., Bischofberger N., Nowak M.A., Desrosiers R.C. \& Wodarz D. (2001). Role of CD8(+) lymphocytes in control of simian immunodeficiency virus infection and resistance to rechallenge after transient early antiretroviral treatment. J Virol Vol. 75, No. 21: pp. 1018710199.

Lin S.W., Cun A.S., Harris-McCoy K. \& Ertl H.C. (2007). Intramuscular rather than oral administration of replication-defective adenoviral vaccine vector induces specific CD8+ T cell responses in the gut. Vaccine Vol. 25, No. 12: pp. 2187-2193.

Lindsay R.W., Darrah P.A., Quinn K.M., Wille-Reece U., Mattei L.M., Iwasaki A., Kasturi S.P., Pulendran B., Gall J.G., Spies A.G. \& Seder R.A. (2010). CD8+ T cell responses following replication-defective adenovirus serotype 5 immunization are dependent on CD11c+ dendritic cells but show redundancy in their requirement of TLR and nucleotide-binding oligomerization domain-like receptor signaling. J Immunol Vol. 185, No. 3: pp. 1513-1521.

Liu J., Ewald B.A., Lynch D.M., Denholtz M., Abbink P., Lemckert A.A., Carville A., Mansfield K.G., Havenga M.J., Goudsmit J. \& Barouch D.H. (2008). Magnitude and phenotype of cellular immune responses elicited by recombinant adenovirus vectors and heterologous prime-boost regimens in rhesus monkeys. J Virol Vol. 82, No. 10: pp. 4844-4852.

Liu J., O'Brien K.L., Lynch D.M., Simmons N.L., La P.A., Riggs A.M., Abbink P., Coffey R.T., Grandpre L.E., Seaman M.S., Landucci G., Forthal D.N., Montefiori D.C., Carville A., Mansfield K.G., Havenga M.J., Pau M.G., Goudsmit J. \& Barouch D.H. (2009). Immune control of an SIV challenge by a T-cell-based vaccine in rhesus monkeys. Nature Vol. 457, No. 7225: pp. 87-91.

Liu Z.X., Govindarajan S., Okamoto S. \& Dennert G. (2001). Fas-mediated apoptosis causes elimination of virus-specific cytotoxic T cells in the virus-infected liver. J Immunol Vol. 166, No. 5: pp. 3035-3041. 
Masopust D., Ha S.J., Vezys V. \& Ahmed R. (2006). Stimulation history dictates memory CD8 T cell phenotype: implications for prime-boost vaccination. J Immunol Vol. 177, No. 2: pp. 831-839.

Mikkelsen M., Holst P.J., Bukh J., Thomsen A.R. \& Christensen J.P. (2011). Enhanced and sustained CD8+ T cell responses with an adenoviral vector-based hepatitis $C$ virus vaccine encoding NS3 linked to the MHC class II chaperone protein invariant chain. J Immunol Vol. 186, No. 4: pp. 2355-2364.

Moskophidis D., Lohler J. \& Lehmann-Grube F. (1987). Antiviral antibody-producing cells in parenchymatous organs during persistent virus infection. J Exp Med Vol. 165, No. 3: pp. 705-719.

Moyron-Quiroz J.E., Rangel-Moreno J., Kusser K., Hartson L., Sprague F., Goodrich S., Woodland D.L., Lund F.E. \& Randall T.D. (2004). Role of inducible bronchus associated lymphoid tissue (iBALT) in respiratory immunity. Nat Med Vol. 10, No. 9: pp. 927-934.

Okuyama T., Li X.K., Funeshima N., Fujino M., Sasaki K., Kita Y., Kosuga M., Takahashi M., Saito H., Suzuki S. \& Yamada M. (1998). Fas-mediated apoptosis is involved in the elimination of gene-transduced hepatocytes with E1/E3-deleted adenoviral vectors. J Gastroenterol Hepatol Vol. 13 Suppl, No. S113-S118.

Pacheco J.M., Brum M.C., Moraes M.P., Golde W.T. \& Grubman M.J. (2005). Rapid protection of cattle from direct challenge with foot-and-mouth disease virus (FMDV) by a single inoculation with an adenovirus-vectored FMDV subunit vaccine. Virology Vol. 337, No. 2: pp. 205-209.

Perreau M., Pantaleo G. \& Kremer E.J. (2008). Activation of a dendritic cell-T cell axis by Ad5 immune complexes creates an improved environment for replication of HIV in T cells. J Exp Med Vol. 205, No. 12: pp. 2717-2725.

Prasad S.A., Norbury C.C., Chen W., Bennink J.R. \& Yewdell J.W. (2001). Cutting edge: recombinant adenoviruses induce CD8 $\mathrm{T}$ cell responses to an inserted protein whose expression is limited to nonimmune cells. J Immunol Vol. 166, No. 8: pp. 4809-4812.

Reyes-Sandoval A., Berthoud T., Alder N., Siani L., Gilbert S.C., Nicosia A., Colloca S., Cortese R. \& Hill A.V. (2010). Prime-boost immunization with adenoviral and modified vaccinia virus Ankara vectors enhances the durability and polyfunctionality of protective malaria CD8+ T-cell responses. Infect Immun Vol. 78, No. 1: pp. 145-153.

Richardson J.S., Yao M.K., Tran K.N., Croyle M.A., Strong J.E., Feldmann H. \& Kobinger G.P. (2009). Enhanced protection against Ebola virus mediated by an improved adenovirus-based vaccine. PLoS ONE Vol. 4, No. 4: pp. e5308.

Rolland M., Tovanabutra S., Decamp A.C., Frahm N., Gilbert P.B., Sanders-Buell E., Heath L., Magaret C.A., Bose M., Bradfield A., O'Sullivan A., Crossler J., Jones T., Nau M., Wong K., Zhao H., Raugi D.N., Sorensen S., Stoddard J.N., Maust B.S., Deng W., Hural J., Dubey S., Michael N.L., Shiver J., Corey L., Li F., Self S.G., Kim J., Buchbinder S., Casimiro D.R., Robertson M.N., Duerr A., McElrath M.J., McCutchan F.E. \& Mullins J.I. (2011). Genetic impact of vaccination on breakthrough HIV-1 sequences from the STEP trial. Nat Med Vol. 17, No. 3: pp. 366371. 
Rowe H.M., Lopes L., Ikeda Y., Bailey R., Barde I., Zenke M., Chain B.M. \& Collins M.K. (2006). Immunization with a lentiviral vector stimulates both CD4 and CD8 T cell responses to an ovalbumin transgene. Mol Ther Vol. 13, No. 2: pp. 310-319.

Schirmbeck R., Reimann J., Kochanek S. \& Kreppel F. (2008). The immunogenicity of adenovirus vectors limits the multispecificity of CD8 T-cell responses to vectorencoded transgenic antigens. Mol Ther Vol. 16, No. 9: pp. 1609-1616.

Shiver J.W., Fu T.M., Chen L., Casimiro D.R., Davies M.E., Evans R.K., Zhang Z.Q., Simon A.J., Trigona W.L., Dubey S.A., Huang L., Harris V.A., Long R.S., Liang X., Handt L., Schleif W.A., Zhu L., Freed D.C., Persaud N.V., Guan L., Punt K.S., Tang A., Chen M., Wilson K.A., Collins K.B., Heidecker G.J., Fernandez V.R., Perry H.C., Joyce J.G., Grimm K.M., Cook J.C., Keller P.M., Kresock D.S., Mach H., Troutman R.D., Isopi L.A., Williams D.M., Xu Z., Bohannon K.E., Volkin D.B., Montefiori D.C., Miura A., Krivulka G.R., Lifton M.A., Kuroda M.J., Schmitz J.E., Letvin N.L., Caulfield M.J., Bett A.J., Youil R., Kaslow D.C. \& Emini E.A. (2002). Replicationincompetent adenoviral vaccine vector elicits effective anti-immunodeficiencyvirus immunity. Nature Vol. 415, No. 6869: pp. 331-335.

Sorensen M.R., Holst P.J., Pircher H., Christensen J.P. \& Thomsen A.R. (2009). Vaccination with an adenoviral vector encoding the tumor antigen directly linked to invariant chain induces potent CD4(+) T-cell-independent CD8(+) T-cell-mediated tumor control. Eur J Immunol Vol. 39, No. 10: pp. 2725-2736.

Sridhar S., Reyes-Sandoval A., Draper S.J., Moore A.C., Gilbert S.C., Gao G.P., Wilson J.M. \& Hill A.V. (2008). Single-dose protection against Plasmodium berghei by a simian adenovirus vector using a human cytomegalovirus promoter containing intron A. J Virol Vol. 82, No. 8: pp. 3822-3833.

Sullivan N.J., Geisbert T.W., Geisbert J.B., Xu L., Yang Z.Y., Roederer M., Koup R.A., Jahrling P.B. \& Nabel G.J. (2003). Accelerated vaccination for Ebola virus haemorrhagic fever in non-human primates. Nature Vol. 424, No. 6949: pp. 681-684.

Sun J.C., Williams M.A. \& Bevan M.J. (2004). CD4+ T cells are required for the maintenance, not programming, of memory CD8+ T cells after acute infection. Nat Immunol Vol. 5, No. 9: pp. 927-933.

Sun Y., Santra S., Schmitz J.E., Roederer M. \& Letvin N.L. (2008). Magnitude and quality of vaccine-elicited T-cell responses in the control of immunodeficiency virus replication in rhesus monkeys. J Virol Vol. 82, No. 17: pp. 8812-8819.

Tatsis N., Fitzgerald J.C., Reyes-Sandoval A., Harris-McCoy K.C., Hensley S.E., Zhou D., Lin S.W., Bian A., Xiang Z.Q., Iparraguirre A., Lopez-Camacho C., Wherry E.J. \& Ertl H.C. (2007a). Adenoviral vectors persist in vivo and maintain activated CD8+ T cells: implications for their use as vaccines. Blood Vol. 110, No. 6: pp. 1916-1923.

Tatsis N., Lin S.W., Harris-McCoy K., Garber D.A., Feinberg M.B. \& Ertl H.C. (2007b). Multiple immunizations with adenovirus and MVA vectors improve CD8+ T cell functionality and mucosal homing. Virology Vol. 367, No. 1: pp. 156-167.

Uger R.A. \& Barber B.H. (1998). Creating CTL targets with epitope-linked beta 2microglobulin constructs. J Immunol Vol. 160, No. 4: pp. 1598-1605.

Uger R.A., Chan S.M. \& Barber B.H. (1999). Covalent linkage to beta2-microglobulin enhances the MHC stability and antigenicity of suboptimal CTL epitopes. J Immunol Vol. 162, No. 10: pp. 6024-6028. 
Utsugi-Kobukai S., Fujimaki H., Hotta C., Nakazawa M. \& Minami M. (2003). MHC class Imediated exogenous antigen presentation by exosomes secreted from immature and mature bone marrow derived dendritic cells. Immunol Lett Vol. 89, No. 2-3: pp. 125-131.

Wu L., Kong W.P. \& Nabel G.J. (2005). Enhanced breadth of CD4 T-cell immunity by DNA prime and adenovirus boost immunization to human immunodeficiency virus Env and Gag immunogens. J Virol Vol. 79, No. 13: pp. 8024-8031.

Yang T.C., Dayball K., Wan Y.H. \& Bramson J. (2003). Detailed analysis of the CD8+ T-cell response following adenovirus vaccination. J Virol Vol. 77, No. 24: pp. 13407-13411.

Yang T.C., Millar J., Groves T., Grinshtein N., Parsons R., Takenaka S., Wan Y. \& Bramson J.L. (2006). The CD8+ T cell population elicited by recombinant adenovirus displays a novel partially exhausted phenotype associated with prolonged antigen presentation that nonetheless provides long-term immunity. J Immunol Vol. 176, No. 1: pp. 200-210.

Yang T.C., Millar J.B., Grinshtein N., Bassett J., Finn J. \& Bramson J.L. (2007). T-cell immunity generated by recombinant adenovirus vaccines. Expert Rev Vaccines Vol. 6, No. 3: pp. 347-356.

Zhao J., Lai L., Amara R.R., Montefiori D.C., Villinger F., Chennareddi L., Wyatt L.S., Moss B. \& Robinson H.L. (2009). Preclinical studies of human immunodeficiency virus/AIDS vaccines: inverse correlation between avidity of anti-Env antibodies and peak postchallenge viremia. J Virol Vol. 83, No. 9: pp. 4102-4111. 


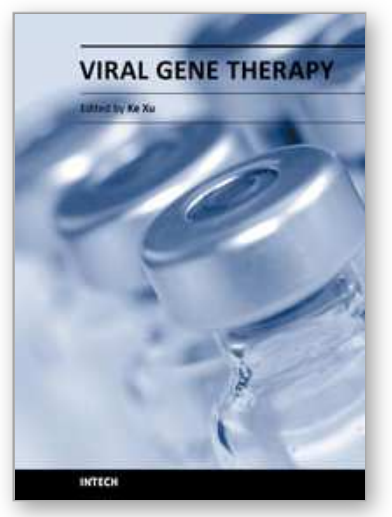

\author{
Viral Gene Therapy \\ Edited by Dr. Ke Xu
}

ISBN 978-953-307-539-6

Hard cover, 450 pages

Publisher InTech

Published online 20, July, 2011

Published in print edition July, 2011

The development of technologies that allow targeting of specific cells has progressed substantially in recent years for several types of vectors, particularly viral vectors, which have been used in $70 \%$ of gene therapy clinical trials. Particular viruses have been selected as gene delivery vehicles because of their capacities to carry foreign genes and their ability to efficiently deliver these genes associated with efficient gene expression. This book is designed to present the most recent advances in viral gene therapy

\title{
How to reference
}

In order to correctly reference this scholarly work, feel free to copy and paste the following:

Peter Johannes Holst and Allan Randrup Thomsen (2011). Harnessing the Potential of Adenovirus Vectored Vaccines, Viral Gene Therapy, Dr. Ke Xu (Ed.), ISBN: 978-953-307-539-6, InTech, Available from: http://www.intechopen.com/books/viral-gene-therapy/harnessing-the-potential-of-adenovirus-vectoredvaccines

\section{INTECH}

open science | open minds

\section{InTech Europe}

University Campus STeP Ri

Slavka Krautzeka 83/A

51000 Rijeka, Croatia

Phone: +385 (51) 770447

Fax: +385 (51) 686166

www.intechopen.com

\section{InTech China}

Unit 405, Office Block, Hotel Equatorial Shanghai

No.65, Yan An Road (West), Shanghai, 200040, China 中国上海市延安西路65号上海国际贵都大饭店办公楼 405 单元

Phone: +86-21-62489820

Fax: $+86-21-62489821$ 
(C) 2011 The Author(s). Licensee IntechOpen. This chapter is distributed under the terms of the Creative Commons Attribution-NonCommercialShareAlike-3.0 License, which permits use, distribution and reproduction for non-commercial purposes, provided the original is properly cited and derivative works building on this content are distributed under the same license. 